\title{
Management of intelligent transport systems applied to sustainable development of motor vehicle transports
}

\author{
Gheorghe Neamțu ${ }^{1}$, Aurel Mihail Țîțu ${ }^{2}{ }^{3}$ \\ ${ }^{1}$ Polytechnic University of Bucharest, 54, Splaiul Independenței, Sector 5, Bucharest, \\ Romania \\ ${ }^{2}$ Lucian Blaga University of Sibiu, 10, Victoria Street, Sibiu, Romania \\ ${ }^{3}$ The Academy of Romanian Scientist, 54, Splaiul Independenței, Sector 5, Bucharest, \\ Romania \\ E-mail: geluneamtu@yahoo.com, mihail.titu@ulbsibiu.ro
}

\begin{abstract}
The scientific paper presents a concrete research carried out by the authors in order to implement technical concepts, so that those interested in this field can learn about a certain way of exposing the problems with regard to the sustainable development of road transport. The use of computer means in the field of motor vehicle transport have taken on a special magnitude in recent times, and the Intelligent Transport Systems (ITS), also known as telematics systems used in the field of transport, comprise a wide range of tools and services deriving from ITS technologies, by using communications and information technology. Below we present a technical and managerial study with engineering nuances, through which readers look at and understand the concept of sustainable development in a global context, showing the possibilities by which ITS are able to provide important data related to the operational efficiency of the entire transport system, the quality of services, infrastructure management, improving road safety, reducing environmental impact, but also how they bring important information and data to managers, operators, passengers and drivers. Finally, some conclusions and subsequent research directions are presented in the field approached.

Keywords: intelligent transport system, information technology, connected and automated mobility, telematics systems, sustainable development, management
\end{abstract}

\section{Introduction}

The automotive industry is undergoing unprecedented technological changes in history, the connected and automated mobility becoming an indispensable objective for today's human beings.

"Transport enjoys a long and successful history in Europe. Europe has a very important role to play in bringing new technologies and innovation to the world. European aircraft, trains and vehicles are synonymous with global quality" [6, page 2].

Sustainable development of transport is a concept that belongs to the field of innovation, i.e. a concept based on the successes of science and technology. The foundation of these innovations can only be provided by scientific research sustained and carried out with effort and high financial funds.

Innovative sustainable development involves leadership that can be based on a country's own scientific developments, on the transfer of achievements to advanced industries in the field.

Information is needed for efficient transport of goods and persons, for sustainable and efficient mobility in a modern economy and society. This is a fundamental requirement, which if not fulfilled, is a great threat to competition in the transport market, but also a poor development of the sustainability of road transport infrastructure. 
The fundamental element that ensures the sustainability of this change is technology, being the solution to solve all problems in the field. Current trends in the sustainable development of this sector are represented by the development of modern technologies, intelligent transport systems that can rigorously manage and streamline transport capabilities, ensure information, security, ergonomics and comfort of passengers.

"Mobility is at a crossroads. In the last century, the road transport sector has progressed a lot. But mobility is now crossing a new frontier - the digital one - where automation and increased connectivity allow vehicles to communicate with each other, with road infrastructure and other road users. These developments go hand in hand with progresses in the field of artificial intelligence" [7].

As regards the environmental protection, intelligent transport systems have a defined role and a strong impact on all transport systems through maximum efficiency and proficiency.

From this point of view, with regard to the road transport system, European leaders have set out ambitious programmes on protecting the environment. These objectives can only be achieved through sustainable and durable development of this system, so that Europe continues to play an important role in the future and also be a leader in terms of a clean, competitive and connected mobility.

"In simple terms, we want to ensure that the best solutions on low carbon emissions, connected and automated mobility, equipment and vehicles are developed, offered and produced in Europe and that we have the most modern infrastructure to support them" [6, page 2].

\section{Sustainable development of automotive transport. Intelligent transport systems}

\subsection{The concept of intelligent transport system and correlation with the sustainable development of automotive transport}

A concrete definition of sustainable development is given by the World Commission on Environment and Development (1986) in our common future report, which has become a reference document, being the first to use the term sustainable development, also known as the Brundtland Report, which states that "sustainable development is the development that seeks to meet the needs of the present time, without compromising the possibility of future generations to meet their own needs".

Sustainability in transport derives from a complex system that aims to ensure mobility needs for today's generation, without contaminating or damaging environmental factors or human health. Applying now maximum efficiency of the consumption of raw materials and energy, the transport system must meet in optimal conditions the economic, ecological and social perspectives of the mobility needs for generations to come.

The sustainable development of motor vehicle transport requires balanced economic growth in terms of economic, social and environmental dimensions, depending directly on the production and energy sectors, which ensure major social prosperity. Sustainable road transport cannot be put aside from economic problems, because it is an integral part of this system. Nowadays, transport specialists and those with responsibilities for environmental protection must resolve as quickly as possible the major problems in this sector, in order to meet pollution reduction, but also to find environmentally friendly and economically viable transport solutions.

In other words, specialists and researchers must find current transport variants that do not pollute the environment and that do not affect human health, and this can be achieved by increasing the energy efficiency of the fuels burned in the thermal engines of the means of transport, the use of more fuel-efficient vehicles, the use of alternative energies for the movement and last but not least, the permanent reduction of waste of any kind resulting from the production or decommissioning of means of transport.

These goals can also be achieved through the development and use of technology in the field of automotive transport.

"Mobility is at a crossroads. In the last century, the road transport sector has progressed a lot. But mobility is now crossing a new frontier - the digital one - where automation and increased 
connectivity allow vehicles to communicate with each other, with road infrastructure and other road users. These developments go hand in hand with progresses in the field of artificial intelligence" [8].

The fundamental element that ensures the sustainability of this change is technology, being the solution to solve all problems in the field. Current trends in the sustainable and durable development of this sector are intelligent transport systems that can rigorously manage and streamline transport capacities by increasing safety, and last but not least, the digitization of payment services in road passenger transport, which leads to an increase in the quality of services.

Intelligent systems used in transport are defined by applications in the field of electronics, information technology and telecommunications and have as their main objectives the reduction of negative effects in transport activity. They shall provide transport operators with those tools used for the collection, analysis, processing, communication and archiving of data resulting from the activity of transport systems. Many projects have been successfully implemented worldwide in this regard.

"Intelligent transport systems refer to a range of digital traffic management systems and information systems covering several modes of transport. The Commission has recognized that the successful and coordinated implementation of such systems is vital for achieving a pan-European and truly integrated transport system, representing an intrinsic part of the future of transport" [5, pages 24-25].

The concept, Intelligent Transport Systems (ITS), first appeared in the United States in 1991. An ITS programme with a value of 660 million dollars was authorized by a document prepared by the US Congress on the efficiency of surface intermodal transport.

The drafted document authorized the Transport Secretariat to coordinate research, develop and carry out tests of intelligent systems throughout the land transport system. The key objective of the document was to build the first fully automated motorway used in road transport.

Subsequently, the law required the Transport Secretariat to report regularly to Congress, presenting security issues and other data on the efficiency of equipment used in the Intelligent Transport systems programme.

In 1991, with the same purpose, the European Association of Participants in the Intelligent Transport Systems Market (ERTICO) was created, which was a consortium of leading European producers who put their shoulder to the promotion and development of ITS markets. This consortium consists of public organizations, representatives of various departments and ministries, large infrastructure, IT and communications operators, users and other organizations.

ITS applications have demonstrated that they are a valid and efficient way of supporting the management and operation of transport services. They can help at [9, page 1]:

$>$ Major reduction of road accidents;

$>$ Increase of the actual capacity of roads without new constructions (increase up to $20 \%$ was demonstrated);

$>$ Reduction of travel time (with an estimate of 1 year at the level of a human life);

$>$ Significant reduction in vehicle pollution (e.g. $\mathrm{CO}_{2}$ emissions);

$>$ Ensure the sustainable and durable development of the road transport system.

ITS application compatibility provides maximum benefits if it is based on a structured strategic framework based on System Architectures for ITS or ITS Architecture.

The term Intelligent Transport System (ITS) is implemented since then in Europe in all transport systems, being designed and created with dedication according to the specifics of each, as follows:

$>$ Intelligent Transport System (ITS) for road transport;

$>$ European Railway Traffic Management Systems (ERTMS), composed of the European Train Control System (ETCS) and GSM-R - GSM, with applications in railway transport;

$>$ River Information Services (RIS) for inland waterway transport;

$>$ Vessel Traffic Monitoring and Information System (VTMIS) for shipping.

Since then, most intelligent system applications have relied on artificial intelligence solutions such as Big Data and Data Mining, i.e. SMART technologies. Because of this, intelligent systems are defined by applied technologies and not by marketing tools. 
The concepts related to the functioning of the ITS fall into three major categories:

1. Coordination - this category includes concepts proposed or implemented by certain operators or they are functions of a road traffic entity;

2. Implementation - the category includes the recommended concepts for implementation, with the greatest potential for benefits;

3. Monitoring - a category that brings together all concepts that can be implemented immediately or after a certain period of time, under the conditions of rapid change from a less developed technology to a highly developed one.

Intelligent transport systems have a wider distribution at the level of states with highly developed economies and a well-developed transport system compared to underdeveloped countries.

The expert documents also show that the idea and momentum that contributed to the emergence of this concept was represented by the problems encountered with the transport of goods and passengers in the great metropolises of the world. They were due to the transport speed in the city, which was much lower than the technical capabilities of the vehicles. To solve the problem, the road infrastructure was initially acted upon, but it was a rather costly problem at the level of the cities.

Mankind had to find alternatives for this problem and they found them: the design, development and implementation of intelligent transport systems. For this reason, humanity has turned its main efforts to these systems, which substantially improve transport activity.

The development of Intelligent Transport Systems consists of the creation of a single information space linking vehicles and road equipment with traffic control centers. ITS are applicable to all transport systems.

The main objectives of these systems are the increased speed of vehicles and the improvement of road safety. They are useful in long-distance road transport, but also in urban areas. In international road transport, these systems create the so-called communications and information-based transport and logistics chains, global navigation monitoring systems (GPS) and automated systems for recording cargo flows.

Intelligent transport systems ensure the safety of road traffic, increase quality in freight and passenger transport and decongest traffic in the major metropolises of the world, making it extremely indispensable to all users, being pedestrians, drivers, passengers or state authorities.

"ITS technology is adopted worldwide in order to increase the capacity of busy roads and reduce travel time." [19].

The usefulness of these systems for pedestrians and passengers consists of: information in public passenger transport; payment card; traffic lights on demand, interactive intelligent network sets, etc.

For drivers the usefulness of these systems is limited to: road traffic information systems via radio channels and messages; tourist planner; dynamic road displays; parking assistance; collection of charges for categories of roads or art pieces for which payments are made, etc.

For cities and other localities these systems are used in: traffic lights control systems; J-Eye (Junction Electronic Eyes) cameras; detection of the level of environmental pollution; noise pollution detectors; intelligent road traffic control panels, etc.

Intelligent Transport Systems are designed to monitor and increase road traffic safety. Here is the qualitative role of an Intelligent Transport System in emergency management.

"ITS can improve the efficiency and safety of transport in a number of situations, i.e. road transport, traffic management, mobility, etc." [17].

Suppose that at the exit of a locality on an express road, at the morning hours, there was a serious traffic accident by entering on the opposite side of a vehicle and colliding it with another vehicle which was travelling regularly. As a result of the accident, numerous human casualties were reported and traffic was blocked on both sides of the road. In this respect, the intelligent e-call system was automatically accessed from one of the vehicles involved in the accident. The signal issued by this system informed the Traffic Control Centre of the city concerned, which had the ability to:

$>$ identify the nature of the accident;

$>$ alert emergency services (ambulance, fire department and police); 
$>$ assure that emergency vehicles are being prioritized at traffic lights in the city;

$>$ urgently inform all nearby road users on-board;

$>$ reorient road traffic to alternative routes.

The flow of information needs to be very fast and secure between all ITS involved for the efficiency of these systems. Their efficiency and effectiveness is high if the systems are integrated. The integration of systems consists of the rapid exchange of information to the control center.

The information is automatically exchanged between vehicles and the Centre of coordination and urban control, it is transmitted and made available to operators and users of public transport, as well as to drivers of vehicles and then displayed through the means of information such as: billboards displaying their messages, information systems on-board, mobile phones of road users, information services on the internet, etc.

The principle of operation of such a system is shown schematically in Figure 1.

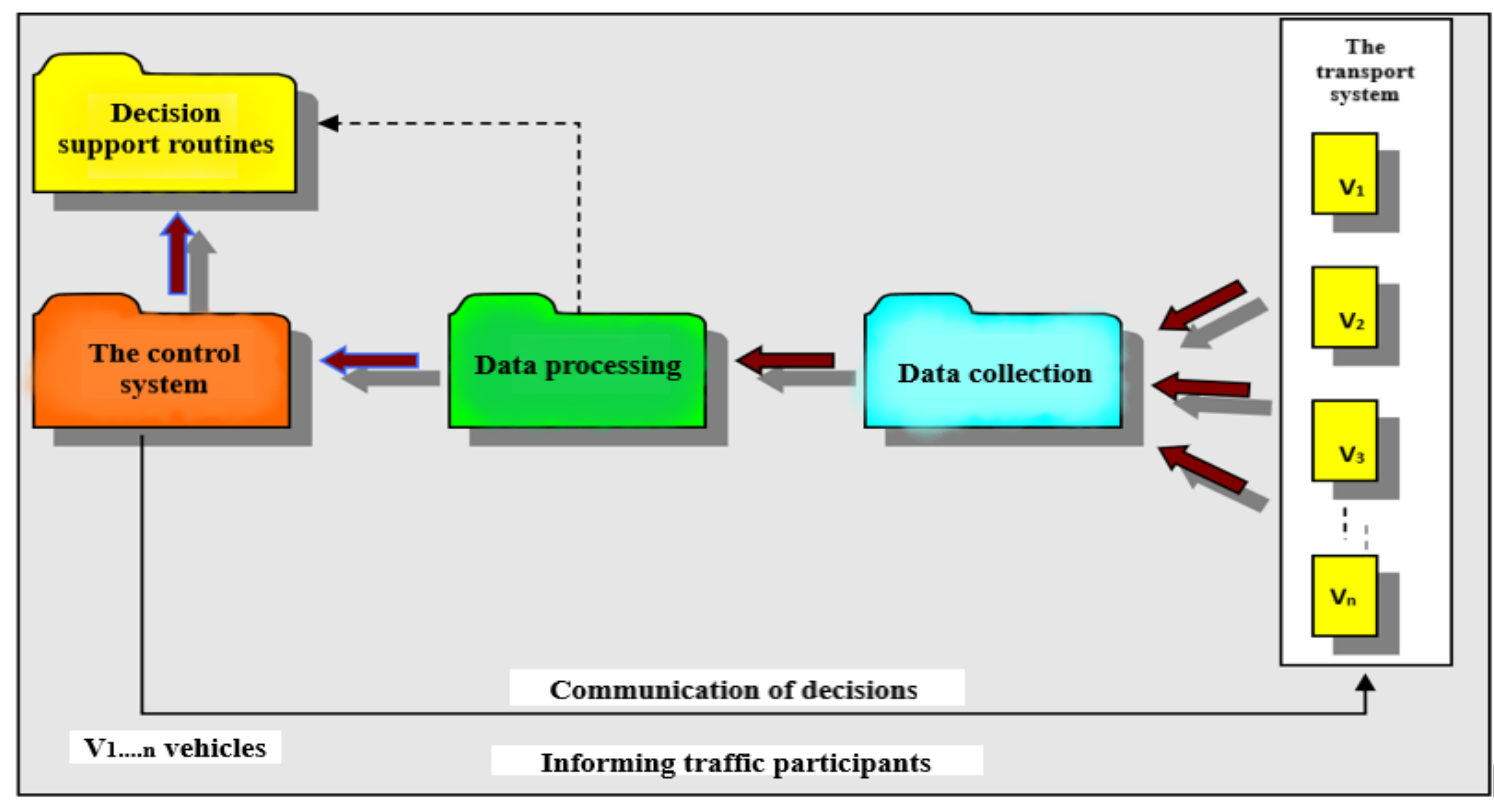

Figure 1. Principle of operation of an Intelligent Transport System

a. Benefits of Automotive Transport by Intelligent Transport Systems

Technology and computing equipment have their applicability today in almost all fields of human activity, and transports are not forgotten in this respect, especially road ones.

ITS (Intelligent Transport Systems), also called telematics transport systems, apply a wide and varied range of services, techniques, applications and tools derived from communications and information technology.

"These systems have the potential to provide significant benefits related to operational efficiency, quality of services, infrastructure management, and at the same time to improve safety, reduce environmental impact and information services for users" [4, page 2].

Intelligent systems have the following utilities in road transport:

$>$ fully automate road traffic and greatly improve traffic management;

$>$ provide full support for public transport operations in urban and inter-urban areas;

$>$ ensure well-timed and acceptable management at request;

$>$ provide information services for travellers;

$>$ are used for travel planning;

$>$ ensure the management of the fleet of vehicles, goods and passengers;

$>$ ensure the management of traffic accidents and incidents;

$>$ provide support for emergency services; 
$>$ provide electronic payment services and collection of fees;

$>$ integrated with advanced on-board technologies.

b. Intelligent Transport Systems used in automotive transport

As mentioned above, these telematics systems have started quite weak, through computer traffic light control systems, which have been designed and re-made to optimize urban traffic flows. Over time, these systems evolved and developed rapidly.

"Transport authorities now accept that the simple construction of several roads is rarely a solution to universal problems related to road traffic congestion. It is essential to find the way for more efficient traffic management on existing roads and increase the use of other modes of transport by passengers and goods. ITS can make a significant contribution to these two objectives" [4, page 12].

Today ITS provide technical support and services for the transport of goods and passengers, both in urban areas and inter-city, as well as on-board, as telematics systems, for the assistance and information of road users.

"The connectivity and accessibility of digital information in real time is revolutionizing logistics operations and the way travel is being planned. This allows goods or passengers to combine modes of transport to follow the most efficient, accessible and environmentally friendly route" [6, page 15].

Figure 2 shows the typical elements of an ITS implementation for vehicle traffic control and management in the city. Such systems are developed gradually, depending on the financial funds allocated and represent the response to road transport policies, carried out by local authorities. The Intelligent Transport Systems Architectures form the basis of the ITS, showing the interoperability of all the applications implemented.

They have been extended to all modes of transport - not only to road, but also to railway, naval and air. In order to be fully fit, it is important that these systems work in a coordinated way throughout the transport network, not only at national, but at European level as well. This can be done using the European ITS Framework Architecture" [4, page 12].

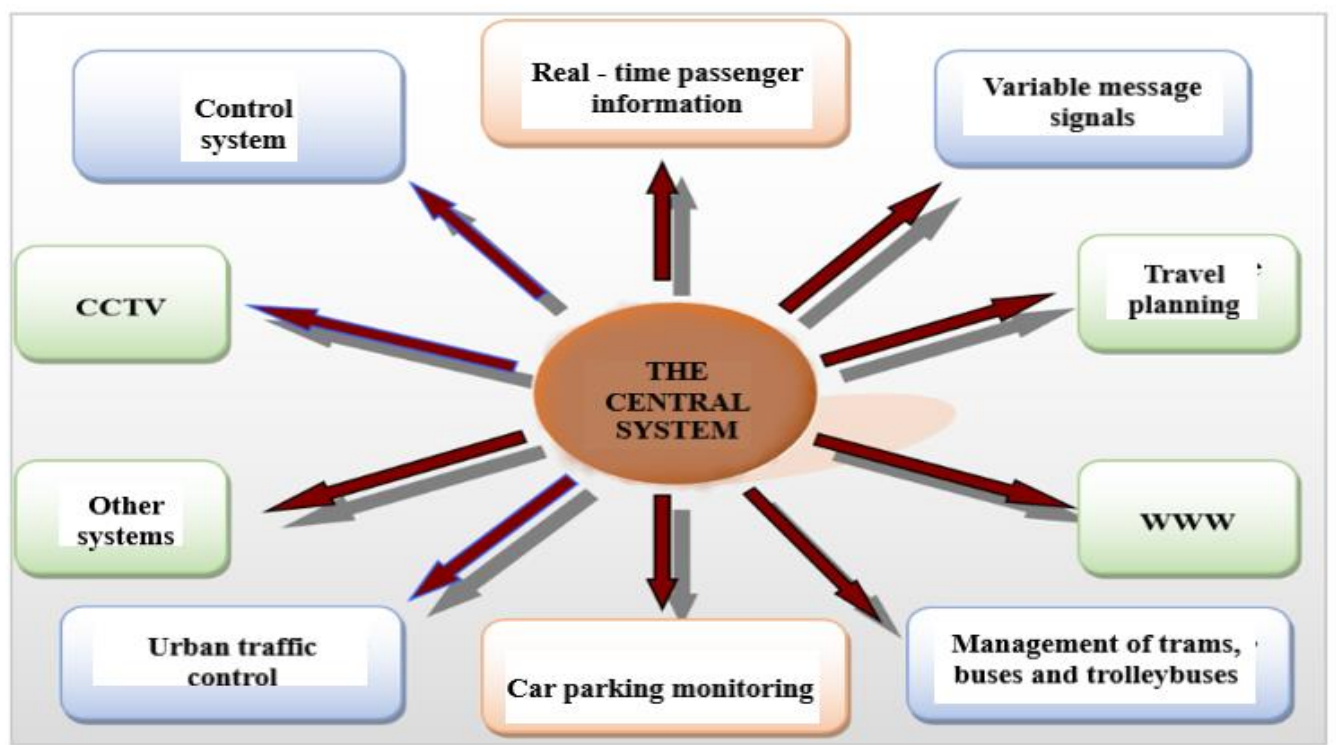

Figure 2. Typical elements of an ITS implementation for urban traffic control and management

\subsubsection{Information to travellers}

ITS have an indispensable role and have taken great and important steps in the field of information of travellers. We say this because providers of such services have demonstrated high capabilities of intelligent systems, being always ready to issue timely information to travellers and other road users 
via well-defined channels before or during the journey. Information flows to beneficiaries have been transmitted to devices mounted on-board, on information message panels mounted in road infrastructure, on GSM terminals, in the form of web services, or on the basis of special kiosks. The information received was the basis of the decisions taken by the beneficiaries on the basis of which they planned or carried out their trips.

"ITS help provide a full travel service: from travel planning and route guidance to booking tickets and parking spaces. Links with tourist services offer additional services, such as hotel reservations, information about places to visit, etc." [4, page 13].

In the field of passenger information, ITS offer the following facilities:

$>$ Advise travellers on changes in routes and exchanges of means of transport, continuously monitor and transmit data on road traffic congestion and weather conditions;

$>$ Due to the interoperability of the systems, they may transmit useful data and information on different terminals, on the internet, in stations or on-board vehicles, through which passengers are informed of the arrival times of the means of transport even before or during the journey.

\subsubsection{ITS in cities and urban agglomerations}

Well-known architectures of the ITS are used in many cities in Europe. They shall ensure clear and precise management, control and coordination of road traffic, public transport operations, control and routing of road traffic for access to different areas, imposing certain regulations for residential parts or areas.

Most road transport operators benefit from the services of these integrated systems at local, European or even global level.

The integration of ITS into traffic management, control and management in cities and urban agglomerations, shall offer the following facilities:

$>$ Align public transport services, providing priorities for traffic signals;

$>$ Inform drivers of road traffic congestion and provide them with alternatives to continue their journey smoothly;

$>$ They support drivers by helping them to quickly find free parking spaces;

$>$ Provide passengers with information enabling them to make comparisons on different modes and transport systems before or during the journey;

$>$ Provide information to travellers, allowing changes to travel plans when traffic incidents or accidents, natural disasters, bad travel weather, interruptions in transport flow or traffic occur.

\subsubsection{ITS for motorways or expressways}

Undesirable events (traffic congestion, traffic incidents or accidents, sections of roads covered with glazed frost, ice or snow, natural disasters, road conditions, works on certain parts, speed limits, etc.) on motorways, express roads or other categories of roads are announced in a timely manner and reach the attention of all road users, due to the rigorous management and coordination of this type of system.

"Many of the proposed Intelligent Transport Systems also involve road surveillance, which is a priority of internal security." [16, pages 367-389].

They can provide data through on-board technology and drivers' smart mobile phones.

"Smartphones with different sensors can be used to track the speed and density of traffic. The accelerometer data on these devices used by drivers is monitored to find out the speed of traffic and the quality of the road. The audio data and GPS tagging of smartphones allow to identify traffic density and possible traffic jams. This was implemented in Bangalore, India, as part of an experimental research system Nericell" [15].

ITS offer the following management for motorways and express roads: 
$>$ Adjustment of access to motorways, express roads and ring roads via automated access arteries;

$>$ Transmission of traffic information and guidance to drivers of transport vehicles by means of information panels or devices on-board;

$>$ Provide traffic speed data on motorways or roads with congestion in order to streamline the flow of road traffic;

$>$ Automatic incident and traffic accident detection systems that automatically send messages to the Traffic Control Centre and provide timely warnings to drivers of vehicles;

$>$ Maintain speed limits through intelligent speed adjustment systems (ISAs), and dynamically modifying these limits depending on road and weather conditions.

ITS architectures enable interoperability not only at regional level, but also at international level, leading to rapid and timely communication where needed. They limit the speed of vehicles on a road depending on the weather conditions, vehicle density, volume of road traffic, etc.

"Some jurisdictions have begun to experience variable speed limits that change along with road congestion and other factors" [18].

\subsubsection{Commodity operations and fleet management}

Worldwide, ITS applications are increasingly used by road transport operators in freight operations and for fleet management.

ITS applications increase the efficiency and effectiveness of operations, encourage the use of different modes and transport systems, leading to improved service quality and road traffic safety.

In this respect, ITS shall support road transport operators by providing the following facilities:

$>$ Schedule and plan the activities of vehicles, goods and drivers;

$>$ Automatically generate reports, flows and transport routes;

$>$ Determine the optimal route for all types of vehicles and their loads;

$>$ Monitor vehicle safety operations and record data and information on-board, providing answers to queries;

$>$ Track and display road transport routes for commercial vehicles, containers and goods during transport, constantly monitoring their physical condition;

$>$ Continuously generate and complete documents accompanying cargo or goods;

$>$ Make it easy to complete electronic documents directly from your driving position anywhere in the world.

\subsubsection{Support Services}

ITS provide road transport with a range of applications, from cashless payment of services, incident management and support for law enforcement activities.

Among them we list:

$>$ SMART CARD payment systems, which allow drivers to pay for parking and passengers to pay for the journey, so that each service provider receives payment for the services provided;

$>$ Automatic charging of vehicles when crossing certain art objectives, road vignette or for access to certain areas of cities for which a tax is payable;

$>$ SOS, transmitted urgently on-board to the Traffic Control Centre, if necessary or in the event of a road accident, with the exact location of the place where the event took place;

$>$ Support and management in the case of special transport, crossing bridges or tunnels;

$>$ Automatic detection of indiscipline in traffic, violation of road legislation by road users.

\section{Intelligent Transport System Architectures in the field of road transport}

Similar to other systems of high complexity, basic strategic structures are used for investment decisions and to incorporate the applications of these systems, through which choices on their design and use are made. These strategic structures are called System Architectures, because they are 
designed and made with dedication to this field. They require coverage of technical, organizational, legal and commercial aspects and can be created at national, regional, urban, sectorial level or for specific services.

These architectures support the ITS from a qualitative point of view, in the sense that:

$>$ Can be planned in a logical way;

$>$ Successfully integrate with other systems;

$>$ Reach the desired performance levels;

$>$ Have the desired behavior;

$>$ It is simple to use and coordinate them;

$>$ It is simple to maintain and expand them;

$>$ Fully meet users' expectations.

The ability to integrate systems greatly increases the potential of architectures. These architectures are successfully implemented at European level as well. According to the European ITS Framework Architecture, applications work together and are made interoperable, including at the level of Community countries. Interoperability includes technical, operational and organizational aspects and involves the harmonious and complementary functioning of the whole system.

The architectures of the Intelligent Transport Systems are necessary for the following reasons:

$>$ Given the standard interfaces between the components of these systems, they ensure a free and open market for services and equipment;

$>$ Allow the existence of the economies of scale in production and distribution, which leads to lower prices for services on the free market for road transport;

$>$ Provide final users with compatible information in the field of road transport;

$>$ Ensure interoperability between components, which can be used for operators and SMEs, when the components of these systems are manufactured by different manufacturers;

$>$ Guarantee investments in these types of systems, while ensuring compatibility;

$>$ Provide an appropriate level of technological independence and allow easy inclusion of new technologies;

$>$ Provide the foundation to understand the purpose and functions of these systems, avoiding conflicting conceptions.

Figure 3 shows the importance of the architectures of Intelligent Transport Systems, which provide road transport operators, manufacturers of these systems, public authorities and users, with systematic mechanisms for determining objectives, facilitating their discussions and providing valuable support to decision-makers.

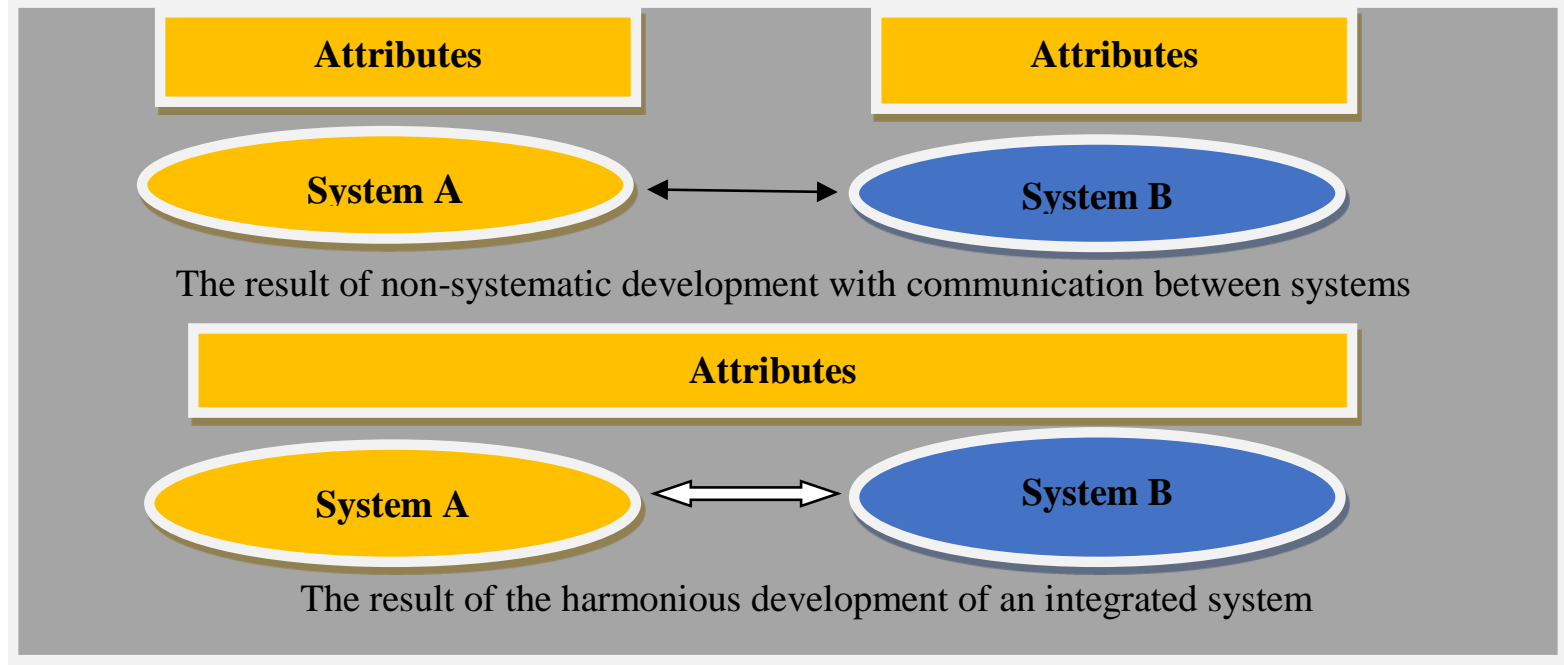

Figure 3. Importance of ITS architectures [4, page 9] 
In the passenger transport, the ITS architectures are designed in such a way that the system must be able to inform passengers about the operational data of public transport, about the duration of the journey, delays, tariffs, arrivals, departures, etc. It shall be able to provide information on public transport services, to inform passengers on-board or before the start of the journey. The system must also be able to provide general (dynamic) information about public transport, passenger safety, arrival time of the next vehicle, to support passengers with special needs in order to inform them about obstacles, hand-operated doors, manual payment systems, etc.

\subsection{Need for the architectures of Intelligent Transport Systems in the field of road transport}

For the integration of ITS applications, as well as for other systems with a high level of complexity, it is necessary to develop a strategic framework in order to make final decisions for designing and making investments in these systems. Such a frame is called the System Architecture.

"Architecture for an Intelligent Transport System will require the coverage of the technical aspects, as well as the organizational, legal and commercial elements" [4, page 3].

Specific characteristics make all system applications work together and be interoperable at European level, according to the European ITS Framework Architecture. This interoperability includes technical, operational and organizational aspects involving the harmonious and complementary functioning of the whole system.

\subsection{Architectures of Intelligent Transport Systems in the automotive field in Europe}

At European level, given the development of ITS, most countries with highly developed economies and industries have created their own national or regional architectures.

Following high-level recommendations, the European Commission has decided to finance the KAREN project since 2000, in order to develop the European ITS Framework Architecture. This architecture was later perfected and expanded within FRAME projects by many countries within their own National or Regional Architectures. The structure and requirements of the European ITS Framework Architecture have been designed in such a way as to be easily accessed by the Community countries in the development of their own architectures.

Figure 4 shows the conceptual model of the European ITS Framework Architecture, on the basis of which some European countries have developed their National ITS Architecture projects such as: ACTIF in France, ARTIST in Italy, TTS-A in Austria and TEAM in the Czech Republic. For this reason, they had a common approach and methodology, but each of them was oriented towards local issues and their development in detail.

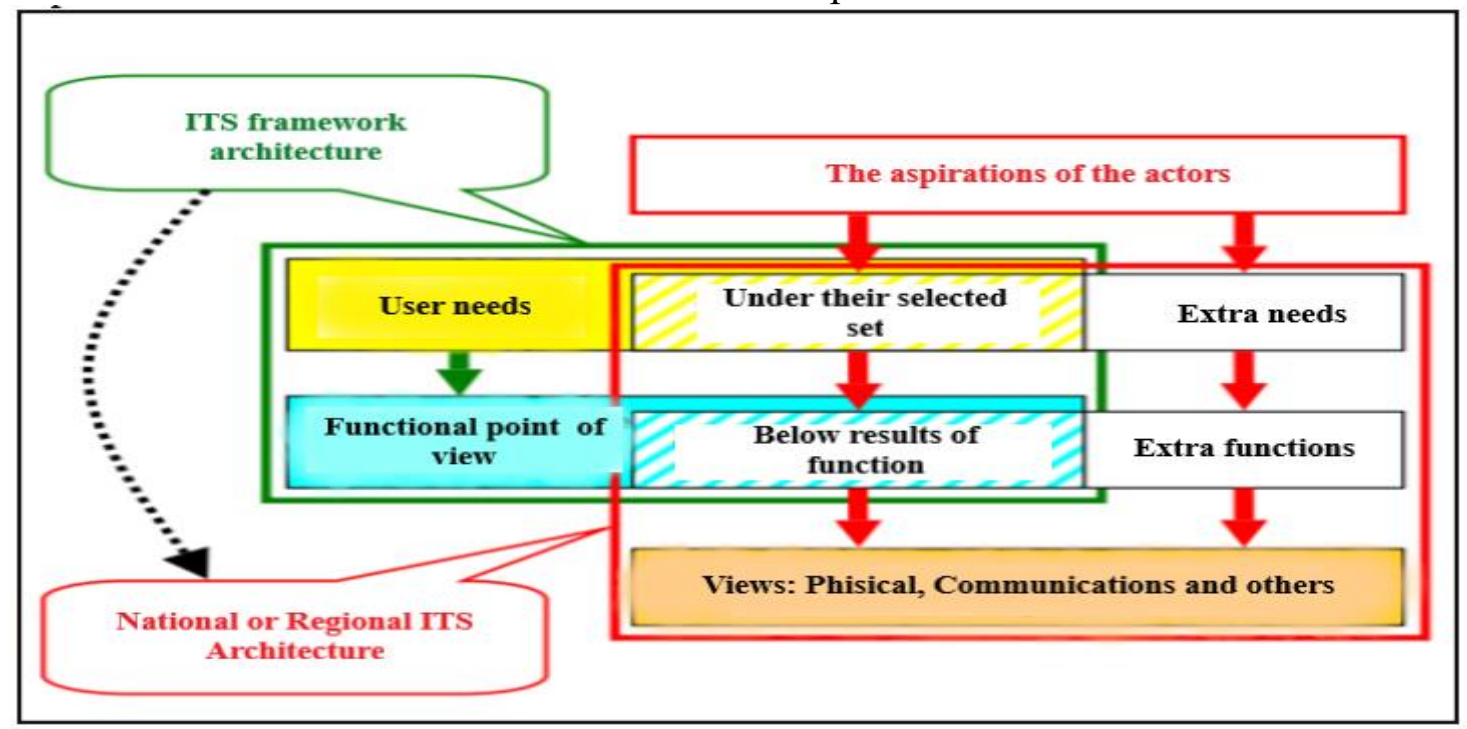

Figure 4. Conceptual model of the European ITS Framework Architecture [4, page 10] 
Outside European territory, countries like Japan, China, Chile and Australia had identical initiatives.

"Despite the approach differences found worldwide, there is an increased desire for the exchange of experience and the exploration of the possibilities of global cooperation on important elements" [4, page 10].

\section{Conclusions:}

The fundamental element that ensures the sustainability of change is technology, being the solution to solve all road transport problems. Thanks to technology, compared to what things once looked like, humanity has become much more efficient, moving much faster and safer, learning better and faster, having easy access to information.

The means by which action can be taken to achieve these wishes are the economic-legislative means, thus acting on fees, authorizations and taxes. The effect of these constraints may lead to a decrease in the use of polluting vehicles with advanced physical or moral wear, technical failures, the reduction of energy consumption, the efficiency and effectiveness of transport activities, the equal redistribution of revenue between transport organizations and the society, as well as the reorientation of the way transport activities are carried out.

It will be necessary to look very carefully at those aspects by which transport organizations cause damage to factors not involved in transport activities, without being held accountable. These are external costs and they are defined by noxious pollution of the earth's atmosphere that produces the greenhouse effect, transmit vibrations in the soil, damaging buildings, roads, works of art, pollute acoustically affecting human health, destroy the flora and fauna of the habitats through which they move, lead to reduced visibility and create traffic jams, especially in the urban environment, decreasing the quality and lifespan of humans.

If some policies specific to the concept of sustainable transport are adopted, this does not mean that the style in which we live is immediately or totally changed, taking radical measures to reduce the needs of travel or restrict the purchase of motor vehicles, but it is necessary to act where the genesis of evil is located, namely, by designing and constructing non-polluting, environmentally friendly means of transport. The measures to be taken in this regard must be staggered in the long term and not in the medium or short term, by applying new political strategies that determine certain factors contributing to the sustainable development of transport, namely: the political factor; specialist teams from motor vehicle and machinery manufacturing organizations. They need to show their training and knowledge in the field of automotive manufacturing, but in this respect, it is very important, but also necessary to involve human society through the activities they carry out on a daily basis.

By improving transport activities, we are developing economically and we increase mobility, but it is necessary to find the state of consistency between the three factors, the ecological factor, the social factor and the economic factor on which the lasting and sustainable development of transport systems depend.

Intelligent transport systems and their architectures increase the quality, efficiency and safety of road transport services, passenger comfort, the ergonomics of the driving station of motor vehicles, reduce and eliminate the discomfort of car travel and save the lives of all road users, being extremely indispensable to all users, be they pedestrians, drivers, passengers or state authorities.

Intelligent transport systems and their architectures contribute and form the foundation for the sustainable and durable development of an efficient automotive transport system.

\section{References}

[1] Adler Y 1975 The design of experiments to find optimal conditions Mir Publ

[2] Bierwerth M, Schwens C, Isidor R, \& et all 2015 Corporate Entrepreneurship and Performance $A$ Meta-Analysis Small Business Economics 45(2) pp 255-278 
[3] Commission on Environment and Development (WCED) 1986 Brundtland Report Our common future

[4] Communities Eu without year EU Road Safety Policy Framework 2021-2030 - Next steps towards Zero Vision Commission Working Paper Brussels

[5] Communities Eu 2004 Planning a modern transport system Guide to the architecture of intelligent transport systems Version 2

[6] Communities Eu 2016 Implementation of the 2011 White Paper on Transport - Roadmap to a Single European Transport Area Brussels SWD (2016) 226 final

[7] Communities Eu 2017 Europe on the Move An agenda for a socially fair transition towards clean competitive and connected mobility for al Brussels COM 283 final

[8] Communities Eu 2018 On the road to automated mobility an EU Strategy for mobility of the future Brussels COM 283 final

[9] Communities Eu 2018 A clean planet for all A European strategic long-term vision for a prosperous modern competitive and climate-neutral econom Brussels Communication from the Commission to the European Parliament the European Council the Council the Economic and Social Committee the Committee of the Regions and the European Investment Bank

[10] ERTICO 2000 aE 2004 Planning a modern transport system Guide to the architecture of intelligent transport systems

[11] Hippel von E 1994 Sticky Information and the Locus of Problem Solving Implication for Innovation Science Management

[12] Juncker J C 2014 Speech by the President of the European Commission European Commission Brussels

[13] Kinard J 1988 Management USA DC Heath and Company Publishing House

[14] Kuratko D, Ireland R, Covin J \& all 2005 A model of middlelevel managers entrepreneurial behavio Entrepreneurship Theory and Practice pp 699-716

[15] Mohan P, Venkata N, Padmanabhan and Ramachandran R 2008 Nericell rich monitoring of road and traffic conditions using mobile smartphones Proceedings of the 6th ACM conference on Embedded network sensor system ACM

[16] Monahan P 2007 War Rooms of the Street Surveillance Practices in Transportation Centres (PDF) The Communications Review 10 (4) pp 367-389

[17] Reducing delay due to traffic congestion [Social Impact] ITS The Intelligent Transportation Systems Centre and Testbed SUOR Social Impact Open Repository Archived from the original on 20170905 Retrieved 20170905

[18] Report (HC 15 2004-05) Tackling congestion by making better use of England's motorways and trunk roads (Full Report) (PDF) National Audit Office 26 November 2004 retrieved 20090917

[19] Smart tech to end freeway congestion Perth Now 20200707 Retrieved 20201007

[20] Teece D 2010 Business models business strategy and innovation Long Range Plan 43(2-3) pp $172-194$

[21] Tompshon A, Fulmer W \& Strickland A 1992 Reading in Strategic Management (p 446) Irwin Boston 